\title{
Enhanced Oil Recovery in Shale Reservoirs by Gas Injection
}

\author{
James J. Sheng, Texas Tech University \\ P.O. Box 43111, Lubbock, TX 79409 \\ James.sheng@ttu.edu \\ 8068348477
}

\begin{abstract}
The current available technique to produce shale oil and gas condensate is through primary depletion using horizontal wells with multiple transverse fractures. The oil recovery factor is only a few percent. There is a big prize to be claimed in terms of enhanced oil recovery (EOR). Because gas price is low and oil price is high, maximizing liquid oil production from gas condensate reservoirs becomes shale producers' top interest.
\end{abstract}

This paper provides the status of enhanced oil recovery (EOR) in shale oil and gas condensate reservoirs by gas injection. It starts with the discussion of possible EOR options in shale reservoirs. For the gas injection option, the huff and puff mode is compared with the gas flooding mode. Different modes of water injection in shale oil reservoirs are also compared. The discussion and comparison show that gas injection is more feasible in shale reservoirs than waterflooding and any other EOR methods. The rest of the paper focuses on review of gas injection in shale reservoirs, which covers the following.

- Mechanisms of gas injection

- Experimental results on huff and puff gas injection

- Simulation results on huff and puff gas injection

- Gas injection in gas condensate reservoirs

This paper summarizes the EOR efforts which has been made in the industry and provides the direction for the industry future efforts to maximize liquid oil production.

\section{Introduction}

The current technique to produce shale oil is through primary depletion using horizontal wells with multiple transverse fractures. The oil recovery in oil-bearing shale reservoirs like the Bakken formation is believed to be less than 10\%. Clark (2009) showed that the results from several methods indicate that the most likely value for recovery factor in the Bakken shale is approximately 7\%. The North Dakota Council website states "With today's best technology, it is predicted that $1-2 \%$ of the reserves can be recovered." (North Dakota Council, 2012). It is certain that a large percentage of oil remains unrecovered without enhanced oil recovery methods. However, no enhanced shale oil recovery method is reported to have been tested in shale reservoirs. Therefore, there is a big prize to be claimed in terms of enhanced shale oil recovery for such low recovery factors and existing immense oil resources.

Classically, methods to enhance oil recovery (EOR) are classified into miscible, chemical, thermal and microbial methods (Lake et al., 2014). In this paper, possibilities to use those methods and the research results are first discussed. Then the preliminary results of the EOR potentials of gas flooding and waterflooding are summarized. Compared with the gas flooding, relatively more research work has been done on huff and puff gas injection. The results from 
experimental and simulation work are summarized. A limited work on gas injection in shale gas condensate reservoirs is also presented. Finally future work to enhance liquid oil production is recommended.

\section{Discussion of Different EOR Options}

Enhanced oil recovery in shale reservoirs is a new topic. To advocate gas injection EOR, it will be helpful to briefly discuss the feasibilities of other OER methods in shale reservoirs and to explain that gas injection may be a preferred EOR method. In this section, the possible application of thermal, chemical, microbial and gas injection methods is discussed.

\subsection{Thermal recovery}

Thermal recovery is generally used to produce viscous heavy oils. The oil viscosities in shale oil reservoirs are very low (less than $1 \mathrm{cP}$ ). At least the mechanism to reduce oil viscosity from thermal methods will not be significant. Apparently, no research work has been done to explore the thermal recovery method in shale oil reservoirs.

\subsection{Chemical methods}

Among chemical methods, surfactants have the most obvious potential to enhance oil recovery, as it is well known that surfactants can change wettability and enhance water imbibition. The literature on shale oil rocks indicates that they are most likely oil-wet (Phillips et al., 2007; Wang et al., 2011). This oil-wet condition makes it difficult for the aqueous phase to penetrate into the matrix and displace the oil out. Surfactants can alter the rock wettability from oil-wet to waterwet or mixed wet (Sheng, 2013a). In terms of enhanced oil recovery in shale oil reservoirs, Shuler et al. (2011) did some surfactant spontaneous imbibition tests. The core slices (not conventional plugs of a few inches in length) they used were 1.5 inches in diameter and $1 / 2$ inches in thickness. Wang et al. (2011) also investigated brine imbibition into the outcrop Pierre shale core slices. Their thicknesses were $0.65-5 \mathrm{~mm}$. Both of these groups used very thin slices because it is well known that the spontaneous imbibition process is very slow (Sheng, 2013b). In practice, if the fracture density is too low, the recovery rate by spontaneous imbibition will be uneconomically slow, because the imbibition rate is inversely proportional to a characteristic length, either linearly, or squared (Mattax and Kyte, 1962; Cuiec et al., 1990; Kazemi et al., 1992; Li and Horne, 2006; Ma et al., 1997; Babadagli, 2001).

\subsection{Microbial methods}

Microbial-enhanced oil recovery (MEOR) is based on biological technology to enhance oil recovery in reservoirs. There are two essential components: Microbes (indigenous or exogenous) and nutrients (in situ or ex situ). At the proper conditions, biopolymers and bio-surfactants are generated (Sheng, 2013c). Therefore, the principles of MEOR are similar to chemical flooding. No report has been published to use MEOR to enhance oil recovery from shale reservoirs. Some polymers may be generated which block ultra-small pores in shale reservoirs.

\subsection{Gas injection}

Gas injection could be in a gas flooding mode or in a huff and puff mode. Gas flooding has been widely used to enhance oil recovery in conventional oil reservoirs, either in simultaneous injection or in water-alternating-gas (WAG) mode. Huff and puff to enhance oil recovery in conventional oil reservoirs has been studied by numerous researchers through laboratory studies 
(Haines and Monger, 1990; Monger and Coma, 1988; Torabi and Asghari, 2010; Torabi et al., 2012), as well as field tests (Bernard and Miller, 1998; Schenewerk et al., 1992; Miller and Gaudin, 2000; Thomas and Monger-McClure, 1991; Monger et al., 1991; Artun et al., 2008). However, to the best of our knowledge, no gas injection has been tried in shale oil or shale liquid-rich reservoirs, although some laboratory tests and simulation studies have been performed. The advances of the subject is reviewed in this paper.

Note the difference of three terms: huff and puff gas injection, gas flooding and cyclic gas injection. In the huff and puff gas injection, the separated gas produced from a well during the puff period is injected back to the reservoir through the same well during the huff period. When the separated gas produced from producers is cyclically injected back into the same field through injectors in the flooding mode, this process is called gas flooding. Cyclic gas could mean both gas flooding and huff-and-puff. As long as the produced gas is injected back to the reservoir through either the huff-and-puff mode or gas flooding mode, and this process is repeated, it is cyclic gas injection.

\section{Huff and puff gas injection versus gas flooding}

Shale oil reservoirs have the natural fracture complexity and may be heavily fractured once they are fractured. When gas flooding is conducted, gas may easily break through producers. This problem can be avoided by huff and puff injection. The injected gas will be dissolved and swell the oil volume. If the injected pressure is high, the miscibility can be achieved. However, there was a concern that the injected gas during the huff period will be re-produced during the puff period. We need to see which process is better, huff and puff or gas flooding. Wan et al. (2013) first evaluated the huff and puff process. Sheng and Chen (2014) did a comparison study to address this question using a reservoir simulation approach. Because of flow symmetry, the model has a single flow unit with two half-fractures at the two side boundaries of the model. One half-fracture is connected to a vertical well. For the gas flooding mode, one half-fracture represents an injector, the other half-fracture represents a producer. In the huff and puff mode, the two half-fractures represents one fracture and are connected two huff-and-puff wells. The distance between the two half-fractures is $200 \mathrm{ft}$, representing the fracture spacing of $200 \mathrm{ft}$. Such a model simulates one fracture performance. The fracture length is $1000 \mathrm{ft}$. The formation height and the fracture height are the same, $200 \mathrm{ft}$. The matrix permeability is $100 \mathrm{nD}$, and the fracture conductivity is $83 \mathrm{mD} f t$. The black oil modeling approach was used. The simulator used was the CMG IMEX (CMG, 2012).

Three production scenarios were simulated. In the first scenario G1, gas injection begins after 10 years of primary production and continues for 60 years. 74.245 MMSCF of gas is injected which corresponds to 30.7 pore volume ( $\mathrm{PV}=430.504 \mathrm{Mbbls}$ in reservoir), and $37.912 \mathrm{MSTB}$ of oil is produced which corresponds to $15.12 \%$ oil recovery factor. If we use a $10 \%$ discount rate, the produced oil of $37.912 \mathrm{MSTB}$ is $11.893 \mathrm{MSTB}$ at the present value. In the second scenario G2, huff and puff gas injection starts after 10 years of primary production. In Sheng and Chen's (2014) simulation models, the huff and puff process has 5 years of injection and 5 years of shut in. The cycle time is too long; thus the huff and puff benefits over gas flooding are not obvious. Therefore, the cycle is changed to 200 days in our new simulation run with the reservoir model being the same as that used in Sheng and Chen (2014). The simulation results are presented below. 
From this new huff and puff model, 2290.8 MMSCF of gas is injected to produce about $32.46 \%$ of original oil in place which corresponds to $25.991 \mathrm{MTB}$ at the present value. For the scenario G3 (gas flooding), gas injection is implemented at the beginning of the development. It can be seen that the scenario G3 has a lower oil production in the first 10 years because only one halffracture is producing instead of two half-fractures in the other two scenarios. As shown in Table 1 , the recovery factor from the scenario G3 in the first 10 years of primary production is $3.4 \%$, whereas both of the recovery factors in the scenarios G1 (primary depletion only) and G2 (primary depletion followed by huff and puff) are 5.75\%. The recovery factors for G3 at the end of 30,50 and 70 years and the oil produced at the present value during the 70 years are all lower than those of the scenarios G1 and G2. Note that in G3, gas flooding is implemented right from the beginning without a primary depletion period. These results show that it is better to implement gas flooding after several years of natural pressure depletion. The results of the three simulation scenarios show that the ultimate recovery factor in the huff and puff scenario doubles those from the other two scenarios. Therefore, huff and puff gas injection after some years of primary production is a much better option. It can be explain this way. After several years of primary depletion, the reservoir pressure is low. Gas injection is needed to increase the reservoir pressure. Because a shale reservoir has ultra-low permeability, the high pressure near the injector cannot propagate to the producer in the gas flooding mode. This problem can be avoided in the huff and puff mode. Thus a combination of early primary depletion and subsequent huff and puff is a better option (Sheng and Chen, 2014).

Kurtoglu (2013) simulated a three-well pattern. A single fractured horizontal well is surrounded by a stimulated reservoir volume (SRV) with a width of $660 \mathrm{ft}$. and a length of $8800 \mathrm{ft}$. The three horizontal wells are parallel with each other and produce in the first 450 days, the central well is used as a $\mathrm{CO}_{2}$ injection well. The performance of huff and puff is compared with that of continuous injection of $\mathrm{CO}_{2}$ (gas flooding). The central well injects from 450 to 1450 days in gas flooding, while it injects 60 days, stops 10 days for soaking, then produces 120 days, and this process is repeated for 6 cycles until 1450 days for the huff and puff mode. The simulation results show that the incremental oil recovery over the primary depletion at the end of 20 years is $0.41 \%$ for the continuous injection, and it is $0.11 \%$ for the huff and puff. The results are probably caused by her model in which only the center well is changed from primary depletion to huff and puff or continuous injection. For such model setup, the huff and puff benefit cannot be realized in the two side wells. But the injection benefit is well captured by the two side wells. Another reason may be that her model does not include molecular diffusivity. Then the soaking benefit is lost. Probably a more important reason is the small natural fracture spacing ( $2.27 \mathrm{ft}$.) in her model. The matrix permeability is around $300 \mathrm{nD}$, and the effective permeability in the SRV is $31 \mu \mathrm{D}$. Such a high permeability model will make the gas flooding feasible. Kurtoglu et al. (2013) characterized the reservoir before conducting the EOR study.

Shoaib and Hoffman (2009) simulated the EOR potential by $\mathrm{CO}_{2}$ injection in the Elm Coulee field of $0.01-0.04 \mathrm{mD}$. Six horizontal wells were in the simulated sector. Their results show that the incremental oil recovery factor from huff and puff $\mathrm{CO}_{2}$ injection of 0.19 pore volumes is only $2.5 \%$ higher than the primary depletion. The cyclic time is three months consisting of injection, shut in for soak and production processes. In the opinion of the author of this paper, the threemonth shut in would definitely too long, thus deteriorate the huff and puff performance. For 
example, Monger and Coma (1988) reported using the soaking time of 18 to 52 days and their results showed the soaking time is less sensitive. Kurtoglu (2013) used 10 day soaking time. The incremental oil recovery factors from $\mathrm{CO}_{2}$ flooding scenarios are about $13 \%$. But in these $\mathrm{CO}_{2}$ flooding scenarios, either 12 vertical injectors or 4 horizontal injectors have to be drilled.

Liu et al. (2014) simulated the EOR potential by $\mathrm{CO}_{2}$ flooding using a sector model of Bakken formation in the Bailey and Grenora areas of the Western North Dakota. The modeled area includes a pair of existing horizontal wells with a spacing of $3000 \mathrm{ft}$. These two wells are known to be in communication. Their results show that $\mathrm{CO}_{2}$ flooding can enhance oil production (recovery) by $43 \%$ when fracture relative permeability curves are used, or 58\% when matrix relative permeability curves are used, compared to their respective cases without $\mathrm{CO}_{2}$ flooding. Those increased oil production percentages correspond to the net $\mathrm{CO}_{2}$ utilization values of 5.86 and 23.175 MSCF/STB, respectively. Their results indicate that the relative permeability curves used in the model are very sensitive. The author of this paper believes that their $\mathrm{CO}_{2}$ flooding results in increased oil production because the permeabilities of their model are in the order of milli-Darcy in the well areas. And the permeabilities are in the order of tens of milli-Darcy in some simulation cells. Such high permeability in the well-connected area is similar to a conventional reservoir. Therefore, $\mathrm{CO}_{2}$ flooding will work.

Table 1 Gas flooding simulation results

\begin{tabular}{|c|c|c|c|}
\hline & $\begin{array}{c}\text { Scenario G1 - } \\
\text { primary+gas } \\
\text { flooding }\end{array}$ & $\begin{array}{c}\text { Scenario G2 - } \\
\text { primary+huff } \\
\text { and puff }\end{array}$ & $\begin{array}{c}\text { Scenario G3 - } \\
\text { gas flooding } \\
\text { only }\end{array}$ \\
\hline $\begin{array}{c}\text { Cumulative Oil Production } \\
\text { (70 years, present value at } \\
10 \%)\end{array}$ & 11.893 MSTB & $25.991 \mathrm{MSTB}$ & $7.744 \mathrm{MSTB}$ \\
\hline $\begin{array}{c}\text { Cumulative Gas Injection } \\
\text { (PV) }\end{array}$ & 30.7 & 947.62 & 26.6 \\
\hline $\begin{array}{c}\text { Overall Oil Recovery (10 } \\
\text { years) }\end{array}$ & $5.75 \%$ & $5.75 \%$ & $3.4 \%$ \\
\hline $\begin{array}{c}\text { Overall Oil Recovery (30 } \\
\text { years) }\end{array}$ & $8.14 \%$ & $22.44 \%$ & $6.68 \%$ \\
\hline $\begin{array}{c}\text { Overall Oil Recovery (50 } \\
\text { years) }\end{array}$ & $11.49 \%$ & $29.65 \%$ & $9.97 \%$ \\
\hline $\begin{array}{c}\text { Overall Oil Recovery (70 } \\
\text { years) }\end{array}$ & $15.12 \%$ & $32.46 \%$ & $13.48 \%$ \\
\hline
\end{tabular}

Waterflooding is the most common used method in conventional reservoirs. When discussing gas injection, such question may be raised: how is waterflooding compared with gas injection in shale oil reservoirs in terms of oil recovery? Sheng and Chen (2014) addressed this question. Three production scenarios of waterflooding have been simulated with the results presented in Table 2. In the first scenario W1, water injection begins after 10 years of primary production and 
continues for 60 years. 27.020 MSTB of water is injected which corresponds to $0.063 \mathrm{PV}$, and 11.627 MSTB of oil is produced which corresponds to $11.9 \%$ oil recovery factor. In the second scenario W2, huff and puff water injection begins after 10 years of primary production. Similar to the gas cases, the huff and puff cycle of 5 years in the original simulation work has been changed to 200 days in the new simulation models. From the new model, 139.25 MSTB of water is injected to produce about $9.69 \%$ of original oil in place. For the scenario W3, water injection is implemented at the beginning of the development. We can understand that the scenario W3 has a lower oil production in the first 10 years because only one half-fracture is used instead of two half-fractures. Interestingly, the recovery factors of different scenarios at the end of 30,50 and 70 years are not very different. These results are consistent with the simulation results from the Middle Bakken Formation by Kurtoglu (2013). Note that water huff and puff is simulated to see whether the pressure maintenance could improve oil recovery significantly, because the huff period can increase the pressure which is depleted during the puff period. Apparently, this benefit was not significant from the results.

Table 2 Water flooding simulation results

\begin{tabular}{|c|c|c|c|}
\hline & $\begin{array}{c}\text { Scenario W1 - } \\
\text { primary+Water } \\
\text { Flooding }\end{array}$ & $\begin{array}{c}\text { Scenario W2 - } \\
\text { primary+huff } \\
\text { and puff } \\
\text { waterflooding }\end{array}$ & $\begin{array}{c}\text { Scenario W3 - } \\
\text { waterflooding }\end{array}$ \\
\hline $\begin{array}{c}\text { Cumulative Oil Production } \\
\text { (present value at 10\%) }\end{array}$ & 11.627 MSTB & 10.137 MSTB & 7.578 MSTB \\
\hline $\begin{array}{c}\text { Cumulative Water Injection } \\
\text { (PV) }\end{array}$ & 0.063 & 0.137 & 0.056 \\
\hline $\begin{array}{c}\text { Overall Oil Recovery (10 } \\
\text { years) }\end{array}$ & $5.73 \%$ & $5.73 \%$ & $3.39 \%$ \\
\hline $\begin{array}{c}\text { Overall Oil Recovery (30 } \\
\text { years) }\end{array}$ & $7.59 \%$ & $8.13 \%$ & $6.41 \%$ \\
\hline $\begin{array}{c}\text { Overall Oil Recovery (50 } \\
\text { years) }\end{array}$ & $9.8 \%$ & $9.22 \%$ & $11.05 \%$ \\
\hline $\begin{array}{c}\text { Overall Oil Recovery (70 } \\
\text { years) }\end{array}$ & $11.9 \%$ & $9.69 \%$ & $8.87 \%$ \\
\hline
\end{tabular}

Comparing the oil recovery factors in Tables 1 and 2, it can been seen that overall gas injection is a better option than water injection. This is because the water viscosity is much higher than gas viscosity (Fai-Yengo et al., 2014); combining the higher viscosity with ultra-low shale permeability, the pressure near the injector cannot propagate to the producer. As shown in Sheng and Chen (2014), the average pressure during water injection still maintains the low pressure level from the primary depletion before water injection, as the high pressure is only distributed near the injector. 
For gas injection, $\mathrm{CO}_{2}$ injection is a well-known EOR method (Jarrell et al., 2002). Its application in shale reservoirs has also been explored. Wang et al. (2010) simulated the EOR potential in the tight $(0.04-2.5 \mathrm{mD})$ Bakken formation in Saskatchewan. Their simulation results indicate that $\mathrm{CO}_{2}$ injection performs much more effectively than waterflooding. And $\mathrm{CO}_{2}$ flooding is a better option than $\mathrm{CO}_{2}$ huff and puff. In their models, one cyclic process includes 10 years of $\mathrm{CO}_{2}$ injection, 5 years of soaking time, and 5 years of production time. Obviously, the huff and puff process is not optimal. Both injection time and soaking time are too long. Kurtoglu (2013) also observed from her simulation results that oil production from $\mathrm{CO}_{2}$ injection is higher than that from waterflooding. Dong and Huffman (2013) simulation results showed that continuous $\mathrm{CO}_{2}$ injection provided four times more oil recovery as compared to waterflooding in the Middle Bakken in the Sanish field (tight formation of $0.04 \mathrm{mD}$ ). A justification to use gas injection is that shale oil or liquid-rich reservoirs are very tight so that gas injection will lead to the highest injectivity. In addition, one important benefit of gas flooding is that natural gas is available in field and the current price is low. On the contrary, water sources are limited in some areas. However, shale-water interactions are not considered in the modeling work. Recently, we observed that the water may help to generate microfractures or open existing microfractures (Morsy et al., 2013a-e, 2014a-c). If so, waterflooding performance might be better than what is presented here. Among the gas injection options, the preliminary results in the literature show that huff and puff gas injection is a better option. The rest of the paper focuses more on huff and puff gas injection.

\section{Mechanisms of gas injection}

Sheng and Chen (2014) compared the oil rates during the primary production and during gas flooding. They found that the difference in oil rate are proportional to the difference in the drawdown pressure during these two processes. Therefore, the drive mechanism in gas flooding is pressure maintenance. In other words, the miscibility is not the dominant mechanism because it is difficult for the injected gas to reach the oil near the producer. Although shale rocks are probably heavily fractured, the natural fractures may be locally distributed. In other words, they are not well connected from an injector to a producer. If such communication exists, gas will flow most rapidly through fractures, but not significantly through the unfractured rock matrix. Thus the gas flooding mechanisms in shale or tight reservoirs are very different from those in conventional reservoirs where gas sweeps through the rock matrix (Hawthorne et al., 2013).

To investigate the mechanisms of huff and puff gas injection, the changes in pressure, oil saturation and oil viscosity at a block $(228,4)$ which is close to the fracture are plotted in Fig. 1. The model was used to generate the scenario G2 in the previous section. During the puff period, the pressure sharply decreases, oil saturation and oil viscosity increase slightly. The oil saturation increases because the oil in the matrix flows to the fracture. The oil viscosity increases because less gas is mixed with the oil as the pressure decreases. During the huff period, the changes are opposite to those changes during the puff period. The sharp change in pressure indicates that the pressure maintenance is an important mechanism. The slight change in oil saturation indicates that swelling mechanism may not be significant. This observation was also confirmed by Hawthrone et al.'s (2013) experiments. Although the oil viscosity does not change significantly during the huff and puff periods, the oil viscosity (about $0.1 \mathrm{cP}$ ) is about three times lower than the oil viscosity $(0.34 \mathrm{cP})$ before the huff and puff process. The lower viscosity is caused by oil mixed with gas. This oil viscosity reduction due to miscibility is an important mechanism. 

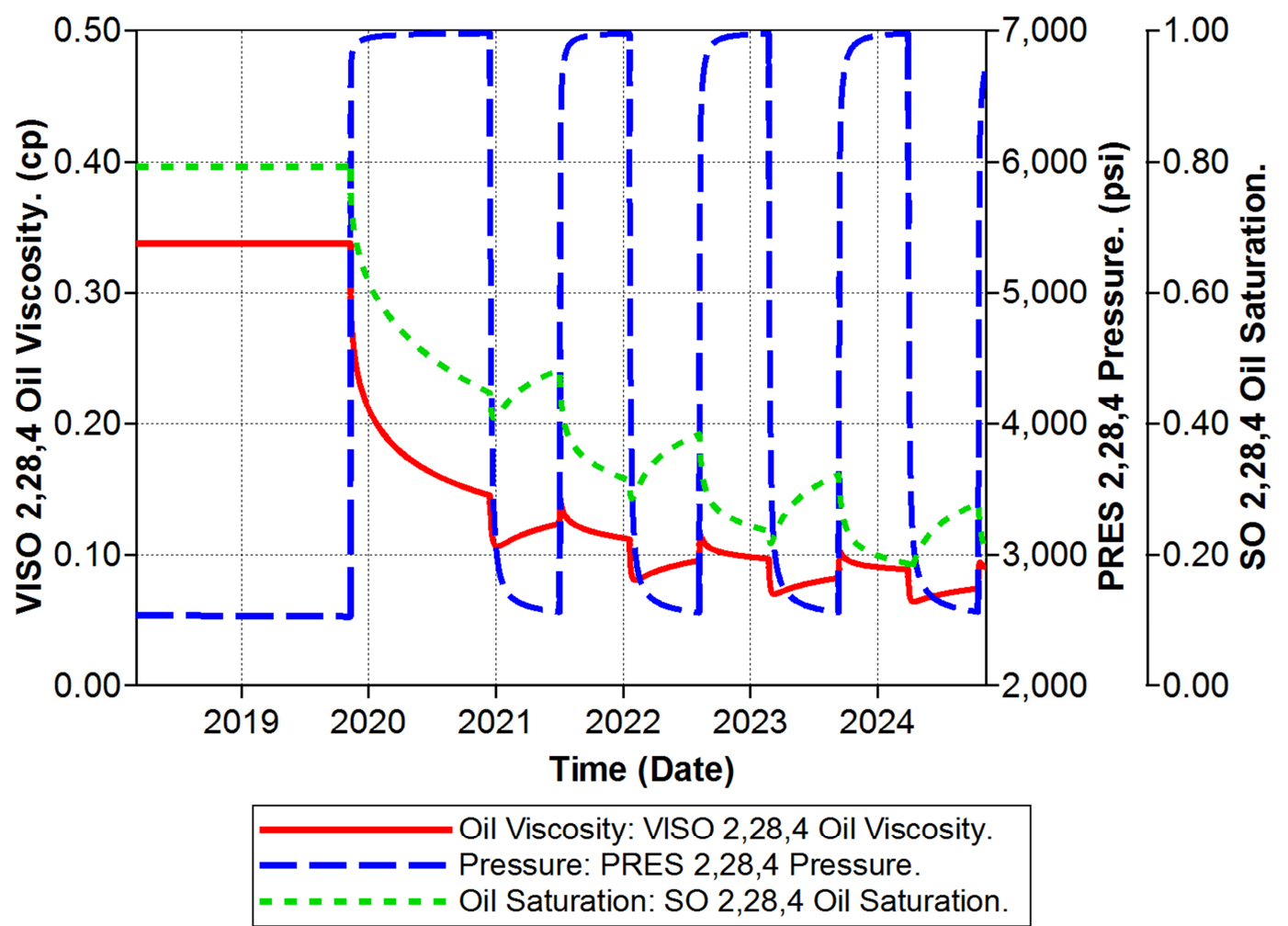

Fig. 1 - Changes in oil viscosity, pressure and oil saturation at the block (2 28 4) near a fracture

Shelton and Morris (1973) conducted theoretical analysis of huff and puff injection of rich gas in viscous-oil reservoirs. They concluded that the most important mechanisms are reduced oil viscosity and increased reservoir energy (pressure maintenance mentioned earlier). And there is a larger energy effect for tight formations.

Relative permeability hysteresis (Carlson, 1981) appears to an important mechanisms in the gas huff and puff process (Denoyelle and Lemonnier, 1987). Haines and Monger (1990) studied natural gas huff and puff using conventional cores in laboratory and found that gas relative permeability hysteresis was an important mechanism, because the oil recovery in a second cycle was improved. The physics related to relative permeability hysteresis is that during the huff period (gas injection), gas phase is continuous phase, gas forms a continuous phase and immediately mobile. During the puff period (pressure depletion), gas in the oil phase forms independent bubbles initially. Gas cannot flow until a critical gas saturation is reached. As a result, gas relative permeability is lower during the puff period than that during the huff period at a same gas saturation.

The well productivity in shale oil and gas reservoirs comes from the horizontal wells with transverse artificial fractures that connect natural fracture complexity (Soliman et al., 2010). The natural fracture complexity provides a network for injected gas to contact matrix materials. The existence of natural fracture complexity may result in fragmented matrices so that the surface area for gas to contact oil is increased, and paths for the oil to flow to the fracture are increased. 
Although natural fracture complexity connected by horizontal well transverse fractures can provide the contacts between injected fluids and the oil-bearing rock, a flooding process may not work because any injected fluids may break through the production wells via the fracture network. Consequently, there is a sweep efficiency problem. Oil recovery from any injection process is directly proportional to the sweep efficiency (Sheng, 2011). Huff and puff injection scheme may solve this problem.

The permeability of matrix materials in oil-bearing shale reservoirs is generally quite low. For example, a middle Bakken reservoir has relatively low porosity (8-10\%) and permeability (average of $0.05 \mathrm{mD}$ ). The reservoir is being developed on 640 and 1280 acre spacings (Sarg, 2012). For such low-permeability and large well spacings, even if some mobility-control agent can be injected to control the flow in fractures, it will take a long time for a displacing fluid to transport from the injector to a producer through matrix. And the required injection pressure may be too high. Again, huff and puff injection scheme may solve this problem.

Apparently, re-fracturing shale reservoirs improves recovery (Vincent, 2011). The proposed huff and puff gas injection may contribute to the process of re-fracturing and thus enhance recovery. Next, we will review the research work done on huff and puff gas injection.

\section{Experimental results on huff and puff gas injection}

Gamadi et al. (2013) are the first who did experimental study on the huff and puff gas injection in shale oil rocks. The experimental set up is simply a shale core plug saturated with oil which is placed in a larger container. The larger container is initially filled up gas at a high pressure. The space between the core plug and the large container is treated as the fracture space. The gas pressure is initially higher than the pressure inside the core plug. Then gas will diffuse into the oil in the core plug. This process represents the huff period. After some gas soaking time, the gas is released and the pressure goes down. The oil pressure inside the core is now higher, and the oil will come out of core. This process represents the puff period. The weight difference of the oil core plug before huff and after puff is the oil produced during one cycle of huff and puff. This process is repeated.

Gamadi et al. (2013) studied the effects of soaking pressure and soaking time. The oil recovery increased with the soaking pressure and soaking time. His results showed that the oil recovery was more soaking-pressure dependence than soaking-time dependence. The soaking pressures used were from 1000 to 3500 psig. The soaking times were 1 to 7 days. It indicated that the pressure maintenance was a dominant mechanism. The oil recovery factors were high (about $10 \%$ and variable depending on other factors), and diminished as more cycles were repeated. The gas used was nitrogen.

Gamadi et al. (2014a) also used $\mathrm{CO}_{2}$. They observed that when the soaking pressure was below $1500 \mathrm{psig}$, the oil recovery factor increased significantly as the pressure was increased. When the pressure was above 1500 psig, the recovery factor was not very sensitive to the soaking pressure any more. Those results might be related to the $\mathrm{CO}_{2}$ minimum miscible pressure (MMP) which was probably close to 1500 psi. It is also implied that the miscibility became more important when $\mathrm{CO}_{2}$ was used than nitrogen. For the cores tested, Eagle Ford cores provided the 
consistently higher oil recovery factors than Mancos cores. The core plug sizes were typical 1.5 in. in diameter and 2 in. in length. By the way, there is a concern of formation damage owing to asphaltene deposition in shale reservoirs (Shahriar, 2014). In their work, a mineral oil was used. Thus it is not known whether the asphaltene deposition could be an issue. Tovar et al. (2014) used the glass beads packed in the core holder to represent fractures. The other parts of the experimental setup were similar to what used by Gamadi et al. (2014a), except that a CT scanner was used in their experimental setup. The huff and puff $\mathrm{CO}_{2}$ injection is repeated. The behavior of $\mathrm{CT}$ number and the characteristics of the produced oil suggested oil vaporization into $\mathrm{CO}_{2}$ as the main mechanism of oil production. They also observed that after some oil was produced from a shale core plug, the weight of the shale oil was increased. The attributed this phenomenon to $\mathrm{CO}_{2}$ adsorption on organic matter in the cores.

Hawthrone et al. (2013) did some experiments which were similar to huff and puff experiments. A small piece of shale rock was exposed to high pressure $\mathrm{CO}_{2}$ for 50 minutes followed by 10 minute flow time to collect liquid oil. Interestingly, they observed that oil recovery rates from small Middle Bakken rocks were essentially the same as those from a conventional square rod sample. Although the oil recovery from a tighter Lower Bakken sample was much lower than the Middle Bakken samples, the recovery was surprisingly high because of very low permeability of the source shale.

Kovscek et al. (2008) did countercurrent flow (flow across one face of the core) and concurrent flow (flow along the length of the core) experiments to investigate oil recovery from siliceous shale $(0.02-1.3 \mathrm{mD})$ by $\mathrm{CO}_{2}$ injection. They observed that the oil recovery was aided by the presence of continuous gas pathways from fracture to matrix that may help $\mathrm{CO}_{2}$ penetrate into the matrix.

Gamadi (2014) also studied the effect of core sizes. Five different Eagle Ford core diameters, 1, $1.5,2,3$, and $4 \mathrm{in}$. with a length of $2 \mathrm{in}$., were used. Although recovered oil volumes increased with larger diameters, the oil recovery factors decreased. The oil recovery factor was defined as the oil produced divided by the initial oil in the core.

\section{Simulation results on huff and puff gas injection}

Wan et al. (2013a) are the first who simulated the performance of huff and puff gas injection in shale oil reservoirs using black oil models. One result worth mentioning is that the cycle time is important to the incremental oil recovery. With a shorter injection time and longer production time, the incremental oil recovery over primary depletion is optimized. Denoyelle and Lemonnier (1987) simulation results also showed that. The incremental oil recovery could reach more than $10-20 \%$. The actual oil recovery factors depend on many factors. It is easy to understand that the oil recovery factor will increase as the fracture spacing is small. In their simulation models, soaking time was not added.

Wan et al. (2013b) later investigate the impacts of fracture spacing and fracture network conductivity on huff and puff performance. Their simulation results show that the effect of fracture conductivity on production performance is not as significant as that of stimulated fracture spacing. For example, for a 100 -foot spacing fracture network, there is about $6 \%$ more oil production owing to the conductivity increase from $2 \mathrm{md}-\mathrm{ft}$. to $4 \mathrm{md}-\mathrm{ft}$., while there is $27 \%$ 
more oil production when the fracture network spacing is decreased from 200 feet to 100 feet.

Gamadi et al. (2014b) simulated the effect of soaking time and soaking pressure (injection pressure) on oil recovery. Not surprisingly, the oil recovery increases with soaking pressure. The oil recovery from one cycle increases with soaking time. However, for a fixed period, a shorter soaking time leads to a higher oil recovery because a longer time is available for production and only a short time is needed to increase the pressure to the allowable level (generally fracture pressure). Monger and Coma (1988) reported that a soak period was required to maximize ultimate oil recovery by cyclic $\mathrm{CO}_{2}$ injection in watered-out Berea cores. However, nine out of fourteen successful $\mathrm{CO}_{2}$ huff and puff field tests experienced soak periods ranging from 18 to 52 days, the process performance appeared to be less sensitive to the soak duration.

Gamadi et al. (2014b) also studied the effect of reservoir heterogeneity. The simulation results show that heterogeneity improves the huff and puff performance (higher oil recovery factor). Their results show that the gross gas utilization which is defined as total gas injected divided by total oil produced is about 7-8 MSCF/STB. The net gas utilization which is defined as (total gas injected minus total gas produced) divided by total gas produced is about $1 \mathrm{MSCF} / \mathrm{STB}$. The field results reported by Monger and Coma (1988) show that the gross gas utilization factors were 1-2 MSCF/STB. Monger et al. (1991) also reported that 56 single well tests showed average $1 \mathrm{MSCF} / \mathrm{STB} \mathrm{CO}_{2}$ utilization of huff and puff in a pressure depleted reservoir in the Appalachian Basin in Easter Kentucky.

Yu et al. (2014a) did a sensitivity study of huff and puff $\mathrm{CO}_{2}$ injection using a calibrated field model. They observed that the most sensitive parameters are injection rate, injection time, number of cycles and $\mathrm{CO}_{2}$ diffusivity. These important parameters are model-dependent or casedependent. In other words, different conditions may show different important parameters. For example, if the formation is very tight, the injection rate is not an important parameter because the injection pressure will soon hit the fracture pressure limit after a short injection time, regardless the injection rate. Artun et al. (2011) did a parametric simulation study of a naturally fractured reservoir (a conventional reservoir), and they found an optimum number of cycles was 2 to 3.

Wan et al. (2014a) used compositional models to study the effect of injected gas composition on the huff and puff gas injection in shale oil reservoirs. Their results show that the oil recovery is increased as the injected gas become richer; $\mathrm{CO}_{2}$ is a good solvent to enhance oil recovery in shale oil reservoir; the oil recovery efficiency (incremental oil per cycle) decreases with the number of cycles. Wan et al. (2014b) also studied the effect of diffusion on oil recovery of gas injection in shale oil reservoirs. The effect is more significant in shale oil reservoirs than in conventional oil reservoirs, and it is a dominant effect when the gas injection rate is low.

Chen et al. (2014) used compositional models of Bakken formation to simulate $\mathrm{CO}_{2}$ huff and puff. The effect of reservoir heterogeneity on oil recovery was simulated. Their results show that the final recovery factor in the huff and puff process is lower than that in the primary recovery, because the incremental recovery in the production stage is unable to compensate the loss in the injection and shut-in stages. In their models, the huff and puff process is from 300 days to 1000 days; the injection pressure is 4000 psi and the bottom hole producing pressure is $3000 \mathrm{psi}$. We 
never had such observation for many models we used. The author of this paper believes that their result is due to the low production history and the low injection pressure. To support the argument, the same model used to generate Fig. 1 of this paper was used to mimic their injection pressure and their injection and production history, as Chen et al. (2014) model is not available to the public. The model results show that the oil recovery factor at 1000 days from the huff and puff process is $2.94 \%$ which is lower than $3 \%$ from the primary depletion. Thus their observation was repeated when our model was used. However, our model shows that the oil recovery factors at the end of 30, 50 and 70 years presented in Table 1 from the huff and puff process are all higher than those from the primary depletion, when the injection pressure of 7000 psi is used. Therefore, Chen et al.'s results are caused by the low injection pressure of 4000 psi which is lower than the initial reservoir pressure of 6840 psi. The injection pressure in the high-pressure reservoir should be raised.

\section{Gas injection in gas condensate reservoirs}

In a gas condensate reservoir, initially the fluid is in gas state. To maximize liquid condensate production, a conventional practice is to maintain the reservoir pressure or even the bottom-hole well pressure of production wells above the dew point pressure by gas and/or water flooding (Hernandez et al., 1999). The reason is that, if reservoir pressure is allowed to decline below the dew point, a considerable volume of valuable condensate may be lost in the reservoir because oil saturation is formed and it is more difficult for the liquid to flow to the surface compared with gas. When oil saturation is below a critical oil saturation, oil cannot be produced using a conventional producing method. In addition, gas productivity declines rapidly once the liquid is formed near the wellbore, because the liquid will block gas flow (Thomas et al., 1995).

In a shale gas condensate reservoir where the formation permeability is very low (nano-Darcy or micro-Darcy), if the well flowing pressure and/or the reservoir pressure is above the dew point pressure, the pressure difference between the reservoir pressure and well flowing pressure which is the drive force to produce gas condensate will be small, especially when the initial reservoir pressure is near the dew point pressure. Then the production rate will be low and the resulting total hydrocarbon recovery will be low as well.

In our earlier work of huff and puff gas injection in shale oil reservoirs, we studied the pressure effect on oil recovery (Wan et al., 2013a, 2013b; Gamadi et al., 2013; Sheng and Chen, 2014; Wan et al., 2014; Gamadi et al. 2014a). If the flowing pressure is above the minimum miscibility pressure (MMP), the injected gas will be fully miscible with the in-situ oil, then the oil viscosity will be decreased to the minimum and the oil will swell to the maximum. The oil recovery will be high. However, the simulation results (Sheng and Chen, 2014) show that higher oil recovery is obtained if a lower bottom-hole flowing pressure is used, even though the flowing pressure is lower than the MMP. The main reason is that as the flowing pressure is lower, the pressure difference between the reservoir and this flowing pressure (drive force) will be higher, so that flow rate will be higher according to Darcy's law. Similarly, in gas condensate reservoirs, to maximize gas and oil production, the pressure drop should be high. The wellbore flowing pressure will be lower than the dew point pressure. Juell and Whitson (2013) did simulation work to find optimal operation conditions for gas condensate shale reservoirs in the depletion mode. They found that the optimal production strategy for wells producing from highly undersaturated gas condensate reservoirs is likely to have an initial period where the flowing 
pressure equals the saturation pressure, followed by a gradual increase in drawdown, towards the minimum bottom-hole pressure that is operationally possible. When that occurs, the liquid oil will be accumulated at the wellbore, and the resulting gas saturation will be low. Then gas condensate rate will be lower, and the corresponding liquid oil rate will be low as well. To solve this problem, the condensate in conventional condensate reservoirs is re-vaporized by lean gas flooding (Standing et al., 1948; Weinaug and Cordell, 1949; Smith and Yarborough, 1968), nitrogen (Aziz, 1982) or $\mathrm{CO}_{2}$ (Chaback and Williams, 1994; Goricnik et al., 1995).

However, in shale reservoirs, formation permeability is so low that any flooding (gas flooding and waterflooding) may not be feasible because the pressure drop from an injector to a producer is large and thus it is very difficult for the pressure to transport from the injector to the producer. To solve this low-permeability problem and to maximize the production drawdown thus liquid oil offtake, the author of this paper has proposed the following scheme to produce gas condensate reservoirs (unpublished yet):

- Huff and puff gas injection mode,

- Flowing bottom-hole pressure lower than the dew point pressure.

Other than that proposed above, there is no discussion about maximizing liquid production in shale gas condensate reservoirs. In dry gas shale reservoirs, Yu et al. (2014b) did a sensitivity study of $\mathrm{CO}_{2}$ injection to enhance dry gas recovery in Barnett reservoirs. They found that $\mathrm{CO}_{2}$ flooding is a good option to enhance gas recovery, but $\mathrm{CO}_{2}$ huff and puff is not because most of the injected $\mathrm{CO}_{2}$ quickly flows back during the puff period.

\section{Concluding remarks}

Based on the literature information and additional results presented in this paper, we can see that gas injection is probably more practical and more efficient than water injection to enhance shale oil recovery; huff and puff gas injection is more effective than gas flooding. In other words, huff and puff gas injection may have the highest liquid oil production potential in shale reservoirs. Therefore, we advocate huff and puff gas injection. Higher soaking pressure, shorter soaking time and longer production time will improve shale liquid oil recovery. Additional benefit of huff and puff gas injection is that produced gas can be re-cycled. Such benefit is related to the current low gas price. With low gas price, operators turn their efforts to produce liquid oil from shale oil and liquid-rich gas condensate reservoirs.

\section{Acknowledgement}

This paper is based upon work supported by the Department of Energy under Award Number DE-FE00243 11.

\section{References}

Artun E., Ertekin T. and Watson R., 2008. Optimized Design of Cyclic Pressure Pulsing in a Depleted Naturally Fractured Reservoir, paper SPE117762 presented at the SPE Eastern Regional/AAPG Eastern Section Joint Meeting, Pittsburgh, Pennsylvania, USA, 11-15 October.

Artun E., Ertekin T. Watson R., and Miller, B. 2011. Performance Evaluation of Cyclic Pressure Pulsing in a Depleted, Naturally Fractured Reservoir with Stripper-Well Production, Petroleum Science and Technology, 29, 953-965. 
Aziz, R.M.A. 1982. Critique on gas cycling operations on gas-condensate reservoirs, paper SPE11477 presented at the Middle East Oil Technical Conference of the Society of Petroleum Engineers held in Manama, Bahrain. March 14-17.

Babadagli, T. 2001. Scaling of Concurrent and Countercurrent Capillary Imbibition for Surfactant and Polymer Injection in Naturally Fractured Reservoirs. SPE J. (December), 465478.

Bernard, J, and Miller, G. P. 1998, Field Case: Cyclic Gas Recovery for Light Oil-Using Carbon Dioxide/ Nitrogen/ Natural Gas, SPE 49169, Presented at the 1998/ SPE Annual Technical Conference and Exhibition, New Orleans, Louisiana, USA, 27-30 September.

Carlson, F.M. 1981. Simulation of Relative Permeability Hysteresis to the Nonwetting Phase, paper SPE 10157 presented at the SPE Annual Technical Conference and Exhibition, 4-7 October, San Antonio, Texas, USA.

Chaback J.J. and Williams, M.L. 1994. p-x Behavior of a rich-gas condensate in admixture with $\mathrm{CO} 2$ and $(\mathrm{N} 2+\mathrm{CO} 2)$, SPERE, 9(1), 44-50.

Chen, C., Balhoff, M.T., and Mohanty, K.K. 2014. Effect of Reservoir Heterogeneity on Primary Recovery and CO2 Huff ' $n$ ' Puff Recovery in Shale-Oil Reservoirs, SPEREE, 17(3), 404-413.

Clark, A. 2009. Determination of Recovery Factor in the Bakken Formation, Mountrail County, ND. Paper SPE 133719 presented at the SPE Annual Technical Conference and Exhibition, 4-7 October, New Orleans, Louisiana, USA.

CMG, 2012. IMEX simulator, Computer modeling Group.

Cuiec, L.E., Bourbiaux, B., Kalaydjian, F. 1994. Oil Recovery by Imbibition in LowPermeability Chalk. SPEFE (September), 200-208.

Denoyelle, L.C. and Lemonnier, P. 1987. Simulation of $\mathrm{CO}_{2}$ Huff 'n' Puff Using Relative Permeability Hysteresis, paper SPE 16710 presented at the SPE Annual Technical Conference and Exhibition, 27-30 September, Dallas, Texas, USA.

Dong, C. and Hoffman, B.T. 2013. Modeling Gas Injection into Shale Oil Reservoirs in the Sanish Field, North Dakota, paper SPE 168827 presented at the Unconventional Resources Technology Conference, 12-14 August, Denver, Colorado, USA.

Fai-Yengo, V., Rahnema, H., Alfi, M. 2014. Impact of Light Component Stripping During CO2 Injection in Bakken Formation, paper SPE 1922932 presented at SPE/AAPG/SEG Unconventional Resources Technology Conference, 25-27 August, Denver, Colorado, USA.

Gamadi, T.D. 2014. Experimental and Numerical Study of the EOR Potential in Shale Oil Reservoirs by Cyclic Gas Injection, $\mathrm{PhD}$ dissertation, Texas Tech University.

Gamadi, T., Elldakli, F., Sheng, J.J. 2014b. Compositional Simulation Evaluation of EOR Potential in Shale Oil Recovery by Cyclic Natural Gas Injection, paper SPE 1922690 (URTeC 1922690) presented at the Unconventional Resources Technology Conference held in Denver, Colorado, USA, 25-27 August 2014.

Gamadi, T.D., Sheng, J.J., and Soliman, M.Y. 2013. An Experimental Study of Cyclic Gas Injection to Improve Shale Oil Recovery, paper SPE 166334 presented at the SPE Annual Technical Conference and Exhibition held in New Orleans, Louisiana, USA, 30 September-2 October.

Gamadi, T.D., Sheng, J.J., and Soliman, M.Y., Menouar, H., Watson, M.C., Emadibaladehi, H. 2014a. An Experimental Study of Cyclic CO2 Injection to Improve Shale Oil Recovery, paper SPE 169142 presented at the SPE Improved Oil Recovery Symposium, 12-16 April, Tulsa, Oklahoma, USA. 
Goricnik B., Sarapa, M., and Csisko, M. 1995. Phase equilibria in a rich-gas condensate-CO2 and natural gas mixtures, NAFTA, 46(9), 371-377.

Haines, H. K, and Monger, T. G. 1990. A Laboratory Study of Natural Gas Huff-n-Puff. Paper 90-78, Presented at the 1990 CIM/SPE International Technical Meeting, Calgary, Canada, 10-13 June.

Hawthorne, S.B., Gorecki, C.D., Sorensen, J.A., Steadman, E.N., Harju, J.A., and Melzer, S. 2013. Hydrocarbon Mobilization Mechanisms from Upper, Middle, and Lower Bakken Reservoir Rocks Exposed to $\mathrm{CO}_{2}$, paper SPE 167200 presented at the SPE Unconventional Resources Conference Canada, 5-7 November, Calgary, Alberta, Canada.

Hernandez, I., Farouq Ali, S.M., and Bentsen, R.G. 1999. First Steps for Developing an Improved Recovery Method for a Gas Condensate Reservoir, paper PETSOC 95-09 presented at the Annual Technical Meeting of Petroleum Society of Canada, June 14 - 18, Calgary, Alberta.

Jarrell, P.M., Fox, C.E., Stein, M.H., Webb, S.L. 2002. Practical Aspects of CO2 Flooding, SPE Monograph Series, Volume 22, Henry L. Doherty Memorial Fund of AIME, Society of Petroleum Engineers Inc., (Ed. Johns, R.T.), Richardson, Texas, USA.

Juell, A.O. and Whitson, C.H. 2013. Optimized Well Modeling of Liquid-Rich Shale Reservoirs, paper SPE 166380 presented at the SPE Annual Technical Conference and Exhibition, 30 September-2 October, New Orleans, Louisiana, USA.

Kazemi, H., Gilman, J.R., and Elsharkawy, A.M. 1992. Analytical and Numerical Solution of Oil Recovery from Fractured Reservoirs with Empirical Transfer Functions. SPERE (May), 219227.

Kovscek, A.R., Tang, G.-Q., and Vega, B. 2008. Experimental Investigation of Oil Recovery From Siliceous Shale by CO2 Injection, paper SPE 115679 presented at the SPE Annual Technical Conference and Exhibition, 21-24 September, Denver, Colorado, USA.

Kurtoglu, B. 2013. Integrated reservoir characterization and modeling in support of enhanced oil recovery for Bakken, PhD dissertation, Colorado School of Mines, Golden, Colorado.

Kurtoglu, B., Sorensen, J.A., Braunberger, J., Smith, S., and Kazemi, H. 2013. Geologic Characterization of a Bakken Reservoir for Potential CO2 EOR, paper SPE 168915 presented at the Unconventional Resources Technology Conference, 12-14 August, Denver, Colorado, USA.

Lake, L.W., Johns, R.T., Rossen, B., and Pope, G. 2014. Fundamentals of Enhanced Oil Recovery, Society of Petroleum Engineers, Richardson, Texas, USA.

Li, K. and Horne, R.N. 2006. Generalized scaling approach for spontaneous imbibitions: an analytical model, paper SPE 77544 presented at the SPE Annual Technical Conference and Exhibition, San Antonio, Texas, USA, 29 September - 2 October.

Liu, G., Sorensen, J.A., Braunberger, J.R., Klenner, R., Ge, J., Gorecki, C.D., Steadman, E.N., and Harju, J.A. 2014. $\mathrm{CO}_{2}$-Based Enhanced Oil Recovery from Unconventional Reservoirs: A Case Study of the Bakken Formation, paper SPE 168979 presented at the SPE Unconventional Resources Conference, 1-3 April, The Woodlands, Texas, USA.

Ma, S., Morrow, N.R., and Zhang, X. 1997. Generalized Scaling of Spontaneous Imbibition Data for Strongly Water-Wet Systems. J. Pet. Sci. Tech., 18, 165-178.

Mattax, C.C., Kyte, J.R. 1962. Imbibition Oil Recovery from Fractured, Water-Drive Reservoir. SPEJ (June), 177-184.

Miller, B. and Gaudin, R. 2000. Nitrogen Huff and Puff Process Breathes New Life into Old Field. World Oil Magazine, 221, 7-8. 
Miller, B.J. and Hamilton-Smith, T. 1998. Field Case: Cyclic Gas Recovery for Light Oil-Using Carbon Dioxide/Nitrogen/Natural Gas, paper SPE 49169 presented at the SPE Annual Technical Conference and Exhibition, 27-30 September, New Orleans, Louisiana.

Monger, T.G., and Coma, J.M. 1988. A laboratory and field evaluation of the CO2 process for light oil recovery. SPE Reservoir Engineering, 3(4), 1168-1176.

Monger, T.G., Ramos, J.C., Thomas, J. 1991. Light Oil Recovery from Cyclic CO2 Injection: Influence of Low Pressures Impure CO2, and Reservoir Gas, SPERE, 6(1), 25-32.

Morsy, S., Gomaa, A., and Sheng, J.J. 2014a. Imbibition Characteristics of Marcellus Shale Formation, paper SPE 169034 presented at the SPE Improved Oil Recovery Symposium, 1216 April, Tulsa, Oklahoma, USA.

Morsy, S., Gomaa, A., Sheng, J.J. 2014b. Improvement of Eagle Ford Shale Formations Water Imbibition by Mineral Dissolution and Wettability Alteration, paper SPE 168985 presented at the SPE Unconventional Resources Conference, 1-3 April, The Woodlands, Texas, USA.

Morsy, S., Gomaa, A., Sheng, J.J., Soliman, M.Y. 2013a. Potential of improved waterflooding in acid-hydraulically-fractured shale formations, paper SPE 166403 presented at the SPE Annual Technical Conference and Exhibition held in New Orleans, Louisiana, USA, September 30-October 2.

Morsy, S. and Sheng, J.J. 2014c. Imbibition Characteristics of the Barnett Shale Formation, paper SPE 168984 presented at the SPE Unconventional Resources Conference, 1-3 April, The Woodlands, Texas, USA.

Morsy, S., Sheng, J.J., Soliman, M.Y. 2013b. Improving hydraulic fracturing of shale formations by acidizing, paper SPE 165688 presented at the SPE Eastern Regional Meeting held in Pittsburgh, Pennsylvania, USA, August 20-22.

Morsy, S., Hetherington, C.J., Sheng, J.J. 2013c. Effect of low-concentration $\mathrm{HCl}$ on the mineralogical, mechanical, and physical properties of shale rocks, paper SPE 165689 presented at the SPE Eastern Regional Meeting held in Pittsburgh, Pennsylvania, USA, August 20-22.

Morsy, S., Sheng, J.J., Hetherington, C.J., Soliman, M.Y., Ezewu, R.O. 2013d. Impact of matrix acidizing on shale formations, paper SPE 167568 presented at the Nigeria Annual International Conference and Exhibition held in Lagos, Nigeria, August 5-7.

Morsy, S., Sheng, J.J., Roland O. Ezewu, 2013e. Potential of waterflooding in shale formations, paper SPE 167510 presented at the Nigeria Annual International Conference and Exhibition held in Lagos, Nigeria, August 5-7.

North Dakota Council, 2012. http://www.ndoil.org/?id=78\&advancedmode=1\&category=Bakken+Basics Accessed on October 25, 2014.

Phillips, Z.D., Halverson, R.J., Strauss, S.R., Layman II, J.M., and Green, T.W. 2007. A Case Study in the Bakken Formation: Changes to Hydraulic Fracture Stimulation Treatments Result in Improved Oil Production and Reduced Treatment Costs, paper SPE 108045 presented the Rocky Mountain Oil \& Gas Technology Symposium, 16-18 April, Denver, Colorado, U.S.A.

Sarg, J. F., 2012. The Bakken - An Unconventional Petroleum and Reservoir System, Final report for Project DE-NT0005672.

Schenewerk, P. A, Thomas, J., Bassiouni, Z. A, Wolcott, Joanne 1992. Evaluation of a South Louisiana CO2 Huff-n-Puff Field Test. SPE 24143-MS, Presented at the 1992 SPE/ DOE Enhanced Oil Recovery Symposium, Tulsa, Oklahoma, USA, 22-24 April. 
Shahriar, M. 2014. Aggregation of Asphaltene Molecules as a Function of Carbon Dioxide Concentration, $\mathrm{PhD}$ dissertation, Texas Tech University, August.

Sheng, J.J. 2011. Modern Chemical Enhanced Oil Recovery: Theory and Practice, Elsevier.

Sheng, J.J. 2013a. Surfactant Enhanced Oil Recovery in Carbonate Reservoirs, Chapter 12 in Enhanced Oil Recovery Field Cases (Sheng, J.J., editor), Elsevier.

Sheng, J.J. 2013b. Comparison of the Effects of Wettability Alteration and IFT Reduction on Oil recovery in Carbonate Reservoirs, Asia-Pacific Journal of Chemical Engineering, 8(1), $154-161$.

Sheng, J.J. 2013c. Introduction to MEOR and Its Field Applications in China, Chapter 19 in Enhanced Oil Recovery Field Cases (Sheng, J.J., editor), Elsevier.

Sheng, J.J. and Chen, K. 2014. Evaluation of the EOR Potential of Gas and Water Injection in Shale Oil Reservoirs, Journal of Unconventional Oil and Gas Resources, 5, 1-9.

Shelton, J.L. and Morris, E.E. 1973. Cyclic Injection of Rich Gas into Producing Wells To Increase Rates From Viscous-Oil Reservoirs, J. Pet. Tech., 25(8), 890-896.

Shoaib, S. and Hoffman, B.T. 2009. $\mathrm{CO}_{2}$ Flooding the Elm Coulee Field, paper SPE 123176 presented at the SPE Rocky Mountain Petroleum Technology Conference, 14-16 April, Denver, Colorado.

Shuler, P., Tang, H., Lu, Z., Tang, Y. 2011. Chemical process for improved oil recovery from Bakken shale, paper SPE 147531 presented at the Canadian Unconventional Resources held in Calgary, Alberta, Canada, 15-17 November.

Smith L.R. and Yarborough L. 1968. Equilibrium Revaporization of retrograde condensate by dry gas injection, SPEJ, 8(1), 87-94.

Soliman, M. Y., East, L., and Augustine, J. 2010. Fracturing Design aimed at Enhancing Fracture Complexity. Paper SPE 130043 presented at the SPE EUROPEC/EAGE Annual Conference and Exhibition, 14-17 June, Barcelona, Spain.

Standing, M.B., Lindblad, E.N., and Parsons, R.L. 1948. Calculated Recoveries by Cycling from a Retrograde Reservoir of Variable Permeability, Trans. AIME, 174(1), 165-190.

Thomas, G. A. and Monger-McClure, T. G. 1991. Feasibility of cyclic CO2 injection for light-oil recovery, SPE Reservoir Engineering, 6(2), 179-184.

Thomas, F.B., Zhou, X., Bennion, D.B., Bennion, D.W. 1995. Towards Optimizing Gas Condensate Reservoirs, paper PETSOC 95-09 presented at the Annual Technical Meeting of Petroleum Society of Canada, June 7 - 9, Calgary, Alberta, Canada.

Torabi, F. and Asghari, K. 2010. Effect of operating pressure, matrix permeability and connate water saturation on performance of $\mathrm{CO} 2$ Huff-n-puff process in matrix-fracture experimental model, Fuel, 89(10), 2985-2990.

Torabi, F., Qazvini, F.A., Kavousi, A., and Asghari, K. 2012. Comparative Evaluation of Immiscible, Near Miscible and Miscible CO2 Huff-n-Puff to Enhance Oil Recovery from a Single-Fracture System (Experimental and Simulation Studies). Fuel, 93, 443-453.

Tovar, F.D., Eide, O., Graue, A., and Schechter, D.S. 2014. Experimental Investigation of Enhanced Recovery in Unconventional Liquid Reservoirs using CO2: A Look Ahead to the Future of Unconventional EOR, paper SPE 169022 presented at the SPE Unconventional Resources Conference, 1-3 April, The Woodlands, Texas, USA.

Vincent, M.C. 2011. Restimulation of Unconventional Reservoirs: When Are Refracs Beneficial? JCPT, 50(5), 36-52. 
Wan, T., Meng, X., Sheng, J.J., Watson, M. 2014a. Compositional Modeling of EOR Process in Stimulated Shale Oil Reservoirs by Cyclic Gas Injection, paper SPE 169069 presented at the SPE Improved Oil Recovery Symposium, 12-16 April, Tulsa, Oklahoma, USA.

Wan, T., Sheng, J.J., Watson, M. 2014b. Compositional Modeling of the Diffusion Effect on EOR Process in Fractured Shale Oil Reservoirs by Gas Flooding, paper SPE 1891403 (URTeC 1891403) presented at the Unconventional Resources Technology Conference held in Denver, Colorado, USA, 25-27 August 2014.

Wan, T., Sheng, J.J., and Soliman, M.Y. 2013a. Evaluation of the EOR Potential in Shale Oil Reservoirs by Cyclic Gas Injection, paper SPWLA-D-12-00119 presented at the SPWLA 54th Annual Logging Symposium held in New Orleans, Louisiana, USA, 22-26 June.

Wan, T., Sheng, J.J., and Soliman, M.Y. 2013b. Evaluation of the EOR Potential in Fractured Shale Oil Reservoirs by Cyclic Gas Injection, paper SPE 168880 or URTeC 1611383 presented at the Unconventional Resources Technology Conference held in Denver, Colorado, USA, 12-14 August.

Wang, D., Butler, R., Liu, H., and Ahmed, S. 2011. Flow-Rate Behavior and Imbibition in Shale, SPEREE, 14(4), 485-492.

Wang, X., Luo, P., Er, V., and Huang, S.-S.S. 2010. Assessment of CO2 Flooding Potential for Bakken Formation, Saskatchewan, paper SPE 137728 presented at the SPE Canadian Unconventional Resources and International Petroleum Conference, 19-21 October, Calgary, Alberta, Canada.

Weinaug C.P. and Cordell J. C. Revaporization of butane and pentane from sand, Trans. AIME, 179(1), 303-312.

Yu, W., Al-Shalabi, E.W., and Sepehrnoori, K. 2014b. A Sensitivity Study of Potential CO2 Injection for Enhanced Gas Recovery in Barnett Shale Reservoirs, paper SPE 169012 presented at the SPE Unconventional Resources Conference, 1-3 April, The Woodlands, Texas, USA.

Yu, W., Lashgari, H., and Sepehrnoori, K. 2014a. Simulation Study of $\mathrm{CO}_{2}$ Huff-n-Puff Process in Bakken Tight Oil Reservoirs, paper SPE 169575 presented at the SPE Western North American and Rocky Mountain Joint Meeting, 17-18 April, Denver, Colorado, USA. 